\title{
Determination of Optimum Maturity Stage for Ocimum sanctum L. Grown under Different Growing Systems in Terms of Therapeutically Active Secondary Metabolites
}

\author{
K.W. ABEYWARDHANA ${ }^{1}$, D.C. ABEYSINGHE ${ }^{1}$, R.M. DHARMADASA ${ }^{2, *}$, A.M.L ATHTHANAYAKE \\ ${ }^{1}$ Department of Plantation Management, Faculty of Agriculture and Plantation Management, Wayamba University of Sri Lanka, \\ Makandura, Gonawila (NWP) \\ ${ }^{2}$ Industrial Technology Institute, Baudhaloka Mawatha, Colombo, Sri Lanka \\ *Corresponding author: dharma@iti.lk
}

Received July 04, 2014; Revised July 11, 2014; Accepted July 15, 2014

\begin{abstract}
Ocimum sanctum L. (Lamiaceae) is therapeutically important medicinal plant used in traditional systems of medicine. Present study was undertaken to determine the optimum growth stage in terms of total phenolic content (TPC), total flavonoid content (TFC) and antioxidant capacity (TAC) of leaf and bark extracts of hydroponically and field grown plants of $O$. sanctum in three different maturity stages. Alkaloids, flavonoids, saponins, tannins and steroid glycosides were qualitatively screened through established protocols. TPC, TFC and TAC were determined by colorimetric Folin-Ciocalteu method, aluminum nitrate method and Ferric Reducing Antioxidant Power (FRAP) assay respectively. Leaf and bark extracts of $O$. sanctum grown under both field and hydroponic conditions, at all three maturity stages exhibited the presence of all phytochemicals tested. TPC, TFC and TAC were increased with the maturity. Significantly higher TPC (8.34 $\pm 0.14 \mathrm{mg}$ GAE /g DW), TFC (132.29 \pm $1.45 \mathrm{mg}$ RE /g DW) and TAC (120.02 $\pm 4.06 \mathrm{mg}$ TE /g DW) were observed in leaf extracts taken from field grown plants at fully maturity stage. The order of increase was just before flowering $<$ just after flowering $<$ fully maturity stage. Presence of higher content of TPC, TFC and TAC in O. sanctum leaves at fully maturity stage, scientifically validate the traditional claims of harvesting of $O$. sanctum leaves at fully maturity stage for better therapeutic value. Moreover, presence of all tested phytochemicals in hydroponically grown plants is positive sign of use of hydroponic system as an alternative growing system for $O$. sanctum.
\end{abstract}

Keywords: antioxidant capacity, growing systems, Ocimum sanctum, maturity stages, secondary metabolites

Cite This Article: K.W. ABEYWARDHANA, D.C. ABEYSINGHE, R.M. DHARMADASA, and A.M.L ATHTHANAYAKE, "Determination of Optimum Maturity Stage for Ocimum sanctum L. Grown under Different Growing Systems in Terms of Therapeutically Active Secondary Metabolites.” World Journal of Agricultural Research, vol. 2, no. 4 (2014): 159-162. doi: 10.12691/wjar-2-4-4.

\section{Introduction}

Ocimum sanctum L. (Family Lamiaceae) is a therapeutically important widely used medicinal plant in traditional systems of medicine for an array of treatments i.e. cold, cough, bronchitis, malaria, stomach disorders, inflammation, heart diseases and various forms of poisoning and as an anti-fertility agent [3,21]. It is known as Maduruthala in Sinhala, Holy Basil in English and Tulsi in Gujarat. Ocimum sanctum is also famous for its religious sanctity, aromatic properties, culinary uses and varied healing properties. Moreover, major chemical constituents in both essential oil and solvent extracts and bioactive compounds such as flavonoids, polyphenols, triterpenes steroids and tannins have been extensively studied by several authors $[2,14,18]$.

Plants have been considered as a rich source of biologically active substances, which are produced due to stress conditions such as water, temperature, radiations and other genetic, environment and agronomic practices [4]. Moreover, therapeutically active substances (Chemical traits) which regulate an important physiological actions on the human body such as polyphenolic compounds, flavonoids, alkaloids, saponins and tannins [8]. Antioxidant, compounds may function as free radical scavengers, complexion agents for pro-oxidant metals, as well as reducing agents and quenchers of singlet oxygen formation [5,9]. Therefore, the importance of the studying for natural anti-oxidants has greatly increased in recent years $[12,14]$. Hydroponic culture is an alternative culturing system of medicinal and other fruit crops in a small area and has been proven as an alternative system for growing of medicinal plants for their secondary metabolite production [11].

Moreover, study of variation of chemical and bioactive constituents with the maturation process of therapeutically important crops is vital important in order to determine the best harvesting time for optimum therapeutic activity. Even though economically/ physiologically optimal growth stage for physical and chemical maturation of most 
of the cultivated crops including Coriandrum sativum [13], have been developed, similar studies or information for medicinal plants are scattered due to most of the plants are still harvested from the wild. However, wild harvesting of medicinal plants can be problematic in terms of variation of secondary metabolites, which are mainly responsible for therapeutic properties, and subsequently it will badly effect on quality of drugs produced from wild harvested plant materials generating potential tragic consequences [7]. Therefore, the present study was undertaken to determine the optimum growth stage in terms of therapeutically important secondary metabolites (preliminary phytochemicals, total phenolic and total flavonoid contents) and antioxidant capacity of leaf, bark extracts of hydroponically, and field grown plants of $O$. sanctum in three different maturity stages.

\section{Materials and Methods}

\subsection{Location}

The experiment was carried out in the experimental plots and laboratory of the Department of Plantation Management, Wayamba University of Sri Lanka, Makandura, Gonawila (NWP) and laboratory of Herbal Technology Section, Industrial Technology Institute (ITI) Colombo from March to July 2014. The experimental plots were situated in the Low Country Intermediate-Zone $\left(\mathrm{IL}_{1 \mathrm{a}}\right)$, at an elevation of $25 \mathrm{~m}$ above mean sea level [17].

\subsection{Chemical and Reagents}

2,4,6-trypyridyl-2-try-azine(TPTZ), 6-hydro xy-2,5,7,8tetramethyl-chroman-2 carboxilic acid (Trolox), Folinciocalteu reagent, Gallic acid, Rutin, L. Ferric chloride $\left(\begin{array}{lll}\mathrm{FeCl}_{3} & 6 \mathrm{H}_{2} \mathrm{O}\end{array}\right)$ were purchased from sigma Aldrich Chemical Co. (St. Louis, Mo). All other chemicals used were of analytical grade.

\subsection{Cultivation and Collection of Samples}

Six weeks old Ocimum sanctum seedlings were planted in University research plots plants at $30 \times 30 \mathrm{~cm}$ spacing. Watering, weeding and manuring were practiced whenever necessary.

Similarly, Ocimum sanctum seedlings were established in hydroponic system.

Leaves and bark samples of $O$. sanctum were collected from field and hydroponically grown plants at three different maturity stages (i.e. just before flowering, just after flowering and fully maturity stage).

\subsection{Extraction of Samples}

Collected bark and leaf samples were air dried for three days at room temperature $\left(28 \pm 2{ }^{\circ} \mathrm{C}\right)$. Samples were coarsely powdered using motor and pestle and sieved with $0.25 \mathrm{~mm}$ mesh. Powdered samples $(0.1 \mathrm{~g})$ were accurately weighed into a $15 \mathrm{~mL}$ centrifuge tube and add $5 \mathrm{~mL}$ of $80 \%$ methanol. The sample was vortexed for $15 \mathrm{~min}$ and placed in a water bath at $60^{\circ} \mathrm{C}$ for $40 \mathrm{~min}$ and vortex procedure was repeated in $10 \mathrm{~min}$ interval. Then samples were centrifuged at 4,000 rpm for $5 \mathrm{~min}$ and supernatant was decanted into a $15 \mathrm{~mL}$ centrifuge tube and the remaining was re-extracted with $5 \mathrm{~mL}$ of $80 \%$ methanol.
Both supernatants were collected and stored at $-20^{\circ} \mathrm{C}$ prior to analysis.

\subsection{Qualitative Screening of Phytochemicals}

Methanolic extracts of samples were screened for alkaloids, flavonoids, saponins, steroid glycosides and tannins according to the method described by reference [10].

\subsection{Quantification of Total Phenolics}

The total phenolic content (TPC) was quantified using a modified Folin-Ciocaltue method [1]. Briefly, $4 \mathrm{~mL}$ of distilled water and $0.5 \mathrm{~mL}$ of plant extract were added into a test tube. Then $0.5 \mathrm{~N}$ Folin Ciocalteu reagent $(0.5 \mathrm{~mL})$ was added and allowed to react $3 \mathrm{~min}$. One milliliter of saturated sodium carbonate solution was mixed and samples were incubated in a water bath for $2 \mathrm{hr}$ at $30^{\circ} \mathrm{C}$. The absorbance was measured at $760 \mathrm{~nm}$ using UV visible spectrophotometer (Shimadzu UV-160). Gallic acid was used as the standard and TPC in one gram of dried plant material was calculated and expressed as milligram of Gallic Acid Equivalent (GAE).

\subsection{Quantification of Total Flavonoids}

Total flavonoid content (TFC) was determined by a colorimetric method described reference [16] with slight modifications. Briefly, $0.5 \mathrm{~mL}$ of the plant extract was diluted with $3.5 \mathrm{~mL}$ of distilled water. Then $0.3 \mathrm{~mL}$ of a $5 \% \mathrm{NaNO}_{2}$ solution was added to the mixture. After 6 minutes, $0.3 \mathrm{~mL}$ of a $10 \% \mathrm{Al}\left(\mathrm{NO}_{3}\right)_{3} \cdot 6 \mathrm{H}_{2} \mathrm{O}$ solution was added, and the mixture was allowed to stand for another 6 minutes. Two milliliter of $2 \mathrm{M} \mathrm{NaOH}$ was added, and the total was made up to $8 \mathrm{~mL}$ with distilled water. The solution was well mixed, and the absorbance was measured immediately at $510 \mathrm{~nm}$ using UV visible spectrophotometer (Shimadzu UV-160). Rutin was used as the standard and TFC in one gram of dried plant material was calculated in addition, expressed as $\mathrm{mg}$ of Rutin Equivalent (RE).

\subsection{Determination of Total Antioxidant Capacity (TAC)}

TAC was determined using Ferric Reducing Antioxidant Power (FRAP) assay [6]. Methanolic extract $(100 \mu \mathrm{L})$ was mixed with $900 \mu \mathrm{L}$ of freshly prepared FRAP reagent of $\mathrm{pH} 3.6$ containing $2.5 \mathrm{~mL}$ of $10 \mathrm{mmol} / \mathrm{L}$, 2,4,6-Tripyridyl-s-Triazine (TPTZ), $2.5 \mathrm{~mL}$ of $20 \mathrm{mmol} / \mathrm{L}$ $\mathrm{FeCl}_{3}$ and $25 \mathrm{~mL}$ of $300 \mathrm{mmol} / \mathrm{L}$ acetate buffer. Absorbance of the reaction was measured at $593 \mathrm{~nm}$ using the spectro photometer (Shimadzu, UV Mini 1240, Japan) after incubating for $4 \mathrm{~min}$. Trolox was used as the standard and TAC in one gram of dried plant material was calculated and expressed as mg of Trolox Equivalent (TE).

\subsection{Statistical Analysis}

Statistical comparison of mean values was performed by General Liner Model (GLM) of ANOVA followed by Turkey Multiple Rang Test using Minitab 15 version and presented means \pm SD. 


\section{Results and Discussion}

This study revealed that alkaloids, flavonoids, saponins, tanins and steroid glycosides are present in both leaf and bark of $O$. sanctum in all maturity stages (Just before flowering, just after flowering and fully maturity) grown under two different growing system (Table 1).

As demonstrated in Figure 1, leaf and bark extracts of $O$. sanctum obtained from both hydroponically and field grown plants exhibited the presence of marked amounts of total phenolics and total flavonoids and TAC at all three maturity stages. Moreover, TPC, TFC and TAC increased with the maturity for both field grown and hydroponically grown plants and the significantly higher $(\mathrm{P}=0.05)$ TPC (8.34 $\pm 0.14 \mathrm{mg}$ GAE /g DW), TFC (132.29 $\pm 1.45 \mathrm{mg}$ RE /g DW) and TAC (120.02 $\pm 4.06 \mathrm{mg} \mathrm{TE} / \mathrm{g}$ DW) were observed in leaf extracts taken from field grown plants at fully maturity stage. The order of increase was just before flowering < just after flowering < fully matunity stage.

Table 1. Qualitative Phytochemical Parameters of Ocimum sanctum Grown under Hydroponic System and Field Oonditions

\begin{tabular}{|c|c|c|c|c|c|c|c|}
\hline Growing system & Growth stage & Plant part & Alkaloids & Flavonoids & Saponins & Tannins & Steroid Glycosides \\
\hline \multirow{6}{*}{ Field grown plants } & \multirow{2}{*}{ Just before flowering } & Leaf & + & + & + & + & + \\
\hline & & Bark & + & + & + & + & + \\
\hline & \multirow{2}{*}{ Just after flowering } & Leaf & + & + & + & + & + \\
\hline & & Bark & + & + & + & + & + \\
\hline & \multirow{2}{*}{ Fully maturity } & Leaf & + & + & + & + & + \\
\hline & & Bark & + & + & + & + & + \\
\hline \multirow{6}{*}{ Hydroponically grown plants } & \multirow{2}{*}{ Just before flowering } & Leaf & + & + & + & + & + \\
\hline & & Bark & + & + & + & + & + \\
\hline & \multirow{2}{*}{ Just after flowering } & Leaf & + & + & + & + & + \\
\hline & & Bark & + & + & + & + & + \\
\hline & \multirow{2}{*}{ Fully maturity } & Leaf & + & + & + & + & + \\
\hline & & Bark & + & + & + & + & + \\
\hline
\end{tabular}

+ : Presence; - : Absence

Increase of TPC, TFC and TAC with the maturity is in agreement with results of previous workers who reported the variation of TPC, TFC and TAC in three Rubus species, Coriandrum sativum and W. somnifera. $[12,13,19]$ with the maturity. Moreover, it was reported that the higher content of TAC in leaves than the stem and roots.

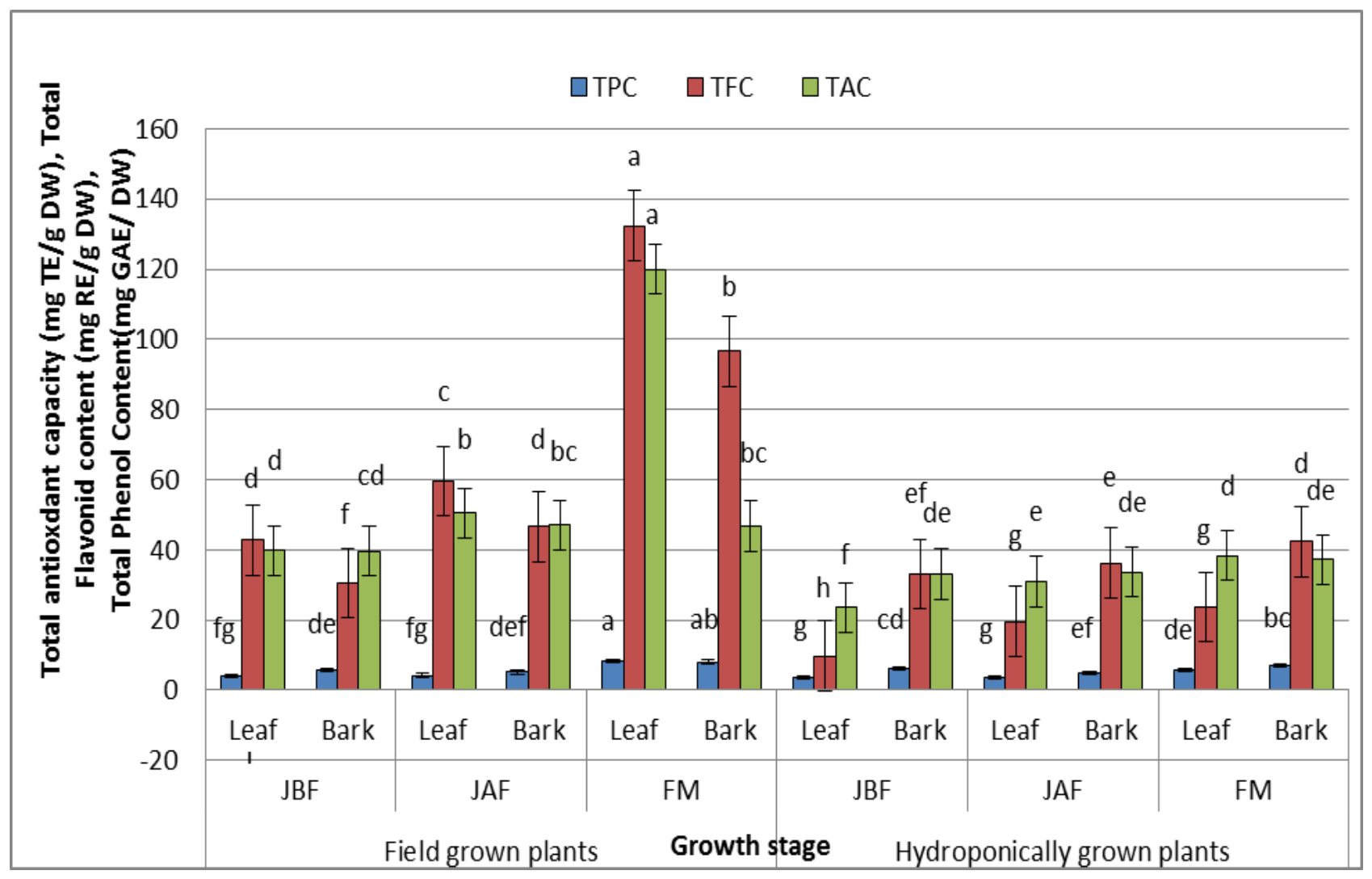

Figure 1. Total phenolic content, total flavonoid content and total antioxidant capacity of Ocimum sanctum at different maturity levels under hydroponic and field conditions

GAE = Gallic acid equivalent; TE = Trolox equivalent; RE = Rutin equivalent; DW = Dry weight; JBF = Just before flowering; JAF = Just after flowering; $\mathrm{MS}=$ Maturity stage

The higher content of TAC, TPC and TFC contents of both leaf and bark extracts in field grown plants were significantly higher than hydroponically grown plants

(Figure 1). Plant secondary metabolites play an important role in relation to biotic (defensive role against herbivore, pest and diseases and attraction of pollinators etc.) and 
abiotic stress conditions such as variation of temperature, water, micro and macro nutrition and light intensity [15]. Accordingly, higher content of TPC, TFC and TAC observed in leaf, bark extracts of field grown plants may be due to high stress conditions in field grown plants, and in contrast, lower content of TPC, TFC and TAC in hydroponic culture may be due to less stress conditions. Moreover, the bark extracts of hydroponically grown plants exhibited significantly higher TPC, TFC and TAC at all maturity stages when compared to the leaf extracts (Figure 1).

\section{Conclusions}

Present study demonstrated the distribution of total phenolic, total flavonoids and total antioxidant capacity of leaf and bark extracts of field grown and hydroponically grown $O$. sanctum in 3 different maturity (just before flowering, just after flowering, fully maturity) stages for the first time in Sri Lanka. The order of increase of TPC, TFC and TAC was just before flowering $<$ just after flowering < fully maturity for both field grown and hydroponically grown plants. Presence of higher content of TPC, TAC and TFC of fully maturity stage, clearly validate the traditional claims of harvesting of $O$. sanctum at fully maturity stage. Moreover, presence of marked total phenolics, total flavonoids, and TAC in leaves at fully maturity stage also scientifically validates the use of leaves of $O$. sanctum at fully maturity. Presence of all tested phytochemicals in hydroponically grown plants is positive sign of use of hydroponic system as an alternative growing system for $O$. sanctum.

\section{Acknowledgement}

Authors wish to express their gratitude to all the staff members of Department of Plantation Management, Wayamba University of Sri Lanka and all staff members of Herbal Technology Section of Industrial Technology Institute (ITI), Colombo 07 for their valuable assistance given to conduct this research study successfully.

\section{Statement of Competing Interests}

No competing interests.

\section{List of Abbreviations}

TPC: total phenolic content ;TFC total flavonoid content ;TAC :antioxidant capacity; FRAP :Ferric Reducing Antioxidant Power; NWP: North western Province; ITI: Industrial technology institute; IL: Low Country Intermediate-Zone; GAE: Gallic acid equivalent; TE: Trolox equivalent; RE : Rutin equivalent; DW : Dry weight

\section{References}

[1] Abeysinghe, D.C., Li, X.., Sun, C., Zhang, W., Zhou, C., and Chen, K, "Bioactive compounds and antioxidant capacities in different edible tissues of citrus fruits of four species" Food chemistry, 104. 1338-1344. 2007.

[2] Ahmed, M., Ahamed R.N., Aladakatti, R.H. and Ghosesawar, M.G. "Reversible anti-fertility effect of benzene extract of Ocimum sanctum leaves on sperm parameters and fructose content in rats," J. Basic Clin. Physiol. Pharmacol, 13(1). 51-9. 2002.

[3] Ali, H., and Dixit, S, "In-vitro antimicrobial activity of flavonoid of Ocimum sanctum with synergistic effect of their combined form,” Asian Pac J. Trop Dis. 2. 396-398.2012.

[4] Anita, B., and Anna, T, "Biotic and abiotic factors affecting the content of the chosen antioxidant compounds in vegetables. Vegetable Crops Research Bulletin” 76. 55-78. 2012.

[5] Bell, E.A., and Charlwood, B.V, The Possible Significance of Secondary Compounds in Plant, Secondary Plant Products, Springer-Verlag, New York, 1980,11-21.

[6] Benzie, I.F.F., and Strain, J.J, "The ferric reducing ability of plasma as a measure of antioxidant power: The FRAP assay," Journal of analytical Biochemistry, 293. 70-76. 1996.

[7] Briskin, D.P, (2000). "Medicinal Plants and Phytomedicines. Linking Plant Biochemistry and Physiology to Human Healt," Plant Physiology, 124. 507-514. 2000.

[8] Chandur, U., Shashidhar, S., Chandrasekar S.B., Bhanumathy M. and Midhun, T, "Phytochemical evaluation and anti-arthritic activity of root of Saussurea lappa," Pharmacologi, 2. 265-267. 2011.

[9] Desider, A.. and Falconi, M,” Prokaryotic $\mathrm{Cu}$, Zn superoxide dismutases," Biochem Soc Trans, 1322-5. Dec. 31(Pt 6).

[10] Farnsworth, N, "Biological and phytochemical screening of plants,” Journal of pharmaceutical Science, 55. 225-276. 1966.

[11] Gontier, E., Clement, A., Tran, T.L.M., Gravot, A., Lievre, K., Guckert, A. and Bourgaud, "Hydroponic combined with natural or forced root permeabilization: A promising technique for plant secondary metabolite production,” Plant Sci., 163. 723-732. 2002.

[12] Jayaprakasha, G.K. and Rao, L.J, "Phenolic constituents from lichen Parmotrema stuppeum (Nyl.) Hale and their antioxidant activity. Zeitschrift für Naturforschung. C,” Journal of Bioscience, 55. N. 11-12. 1018-1022. 2000.

[13] Kamel Msaada, Karim Hosni, Mouna Ben Taarit, Thouraya Chahed, Mohamed Elyes Kchouk, Brahim Marzouk,"Changes on essential oil composition of coriander (Coriandrum sativum L.) fruits during three stages of maturity," Food Chemistry, 102 ( 4 ). 1131-1134. 2007.

[14] Kathirvel, P. and Ravi, S, Chemical composition of the essential oil from basil (Ocimum basilicum Linn.) and it's in vitro cytotoxicity against HeLa and HEp-2 human cancer cell lines and NIH $3 T 3$ mouse embryonic fibroblasts, Nat Prod Res.,Sep 22. 2011. (Epub ahead of print).

[15] Kaufman, P.B., Cseke, L.J., Warber, S., Duke, J.A. and Brielmann, H.L, Natural Products from Plants, CRC Press, Boca Raton, FL. 1999.

[16] Liu, M., Li, X.Q., Weber, C., Lee, C.Y., Brown, J. and Liu, R.H, "Antioxidant and Anti-proliferative Activities of Raspberries," $J$. Agric. Food Chem., 50. 2926-2930. 2002

[17] Panabokke, C. R,Soil and agroecological environmenst of Sri Lanka, Natural Resources Energy and Science Authority,Colombo,Sri Lanka. 1996.

[18] Rahman, S., Islam, R., Kamruzzaman, M., Alam, K. and Jamal, A.H.M, "Ocimum sanctum, L. A Review of Phytochemical and Pharmacological Profile,” American Journal of Drug Discovery and Development, 1-15. 2011.

[19] Sharma, R. K., Samant, S. S., Sharma, P. and Devi, S, "Evaluation of antioxidant activities of Withania somnifera leaves growing in natural habitats of North- west Himalaya, India," Journal of Medicinal Plants Reaserch, 6 (5). 657-661. 2011.

[20] Shiow, Y., Wang and Hsin-Shan Lin, "Antioxidant Activity in Fruits and Leaves of Blackberry, Raspberry, and Strawberry Varies with Cultivar and Developmental Stage,” J. Agric. Food Chem., 48 (2). 140-146. 2000.

[21] Singh, E., Sharma, S., Dwivedi, J. and Sharma, S, "Diversified potentials of Ocimum sanctum Linn. (Tulsi): An exhaustive survey,” J. Nat. Prod. Plant Resour; 2(1). 39-48. 2012.

[22] Siriwardana, A.S., Dharmadasa, R.M., Samarasinghe, K, "Distribution of withaferin A, an anticancer potential agent, in different parts of two verities of Withania somnifera (L.) Dunal grown in Sri Lanka," Pakistan Journal of Biological Sciences, 16(3).141-144. 2013. 